\title{
The Mode Change of Tax Collection in China under the Background of
}

\section{Big Data}

\author{
Dongdong Wang ${ }^{1, a}$ \\ ${ }^{1}$ Tianjin University, Tianjin, 300072, China \\ aemail:
}

Keywords: Big data; Tax collection and management model; Dilemma; Change

\begin{abstract}
With the advent of the era of big data, the current tax collection and administration mode in China are faced with severe challenges and are gradually getting into a dilemma facing a transition pressure. At the same time, big data technology is also showing new vigor and vitality with providing a powerful technical means for the management of the data. In addition, it also brings the data management, new methods and new pattern matching with new opportunities for the collection and management mode transformation. Based on the The author's study and practice experience, this paper firstly analyzed the traditional mode of tax collection difficulties, and then put forward the idea of the transformation about the mode of tax collection and administration. Big data has unique advantages in strengthening tax risk management and optimizing tax services. This will have a far-reaching impact on China's tax collection and management model, and will become an important part of the new tax collection and management model.
\end{abstract}

\section{Introduction}

Because of the slow data processing, the analysis of tax data has hysteresis and passivity under the traditional data model of the tax department. Tax source monitoring and risk management can not be solved in advance. It was always making punishment and remediation after monitoring and risk management, so it is difficult to adapt to changes in society and taxpayers. At the era of big data, data processing speed is very fast and it can solve the problem timely and can find problems ahead of time; in addition, the data processing can be timely warning to the taxpayer and can prevent the tax risk.

\section{The Traditional Mode of Tax Collection Difficulties}

Tax administration strength is difficult to adapt to the change of tax sources. The way of "people monitor people" tax collection does not adapt to the expansion of taxpayer. In recent years, the number of taxpayers has increased rapidly, while tax managers have hardly increased. It is more and more difficult to control the drain of tax sources, and it is also difficult to adapt to the development of the situation by relying solely on the assessment and inspection by tax personnel. According to the provisions of the tax administrator system, the tax administrator has 6 major categories and 17 responsibilities; This requires a high level of ability and quality. Tasks of collect administrator are very complicated with many works. Therefore, the phenomena like managements of bad households and unable management of households are more prominent. With the advance of "replacing business tax with value-added tax", per capita household management is still growing. Moreover, the taxpayers' establishment, cancellation and purchase of tickets have changed frequently, and the existing tax collection and management methods are becoming more and more 
inadequate to meet the needs of tax source management changes.

Land management can not meet the requirements of taxpayers' trans regional management. It mainly shows that the mode of territorial management is not compatible with the globalization and the characteristics of trans regional management. With the development of society and the division of labor, taxpayer mixed operation, diversification, trans regional and even cross-border operations have become the norm. Enterprise management location, place of production and account and sales locations are increasingly separated from each other. Mutual investment between enterprises and business integration with electronic and intelligent management are increasingly appeared. Large and complex financial transactions and e-commerce are continuous to grow, requiring breaking the existing administrative region management. However, the existing management methods can not grasp the comprehensive information of enterprises across the region, so it implements the low-level, extensive and flat management methods.

The tax law enforcement service is difficult to meet the requirements of collection and management efficiency. Too much of the original tax management way on the registration, approval and control makes the process become more and more tedious. Thus, the changing situation and requirement of taxpayers to safeguard the interests of taxpayers are incompatible. In recent years, the State Administration of Taxation is phasing out of nearly one third of examinations and approvals. We have strengthened the managements through filing and non-licensing so that to prevent the tax risks after abolition of approval for the prevention. However, the efficiency of tax collection and management has not been improved qualitatively. At present, the problems including difficult buying and canceling tickets reflected by taxpayer, unsatisfied with special and personalized services, repeated collection of tax materials, tax assessment and repeated tax check, huge-crowd strategy and ticket control tax source management mode are difficult to adapt to the rapid development of information society reality are the demonstrations and choice of lagging law enforcement service.

Tax collection and management techniques are difficult to meet the requirements of the digital age. At present, the degree of social informatization is not uniform, and the information caliber is incomplete. Both structural data and non structural data are available. At present, the tax authorities pay more attention to structured data, and do not pay attention to non structural data, which increases the difficulty of tax management. For example, WeChat, Alipay and other network also outside the collecting the management information of tax department; in addition, the tax department invoice management also is difficult to include varieties, commodity name, specifications, size and so on. Further, tax assessment and tax inspection are also more dependent on taxpayers' paper books, and many local tax assessment mainly relies on experience to carry out without assessment. The tax service still stays at a shallow level, and the taxpayers' propaganda, consultation and counseling are still in a separate and scattered state. At the same time, because of the different sources of information and the different caliber of information, the utilization rate of equipment and information is very low, and the information is only entered without analysis and utilizing. This causes serious accumulation of information and is lack of openness and sharing; in addition, it also resulted in low efficiency of management and dead information with little value. Therefore, the existing management methods are not compatible with modern, electronic and digital age characteristics.

\section{Conception of Transformation of Tax Collection and Management Mode}

Build new tax collection and management mode. The new pattern of tax collection is based on a large data base so that to solve the problem of asymmetric information for the target collection; 
it also takes the information flow as the main line, and takes the data comparison as the core. A new working pattern of computer processing and manual processing combination, namely is "pipe system" mode of tax collection. Adhering to the top-level design concept, the new tax collection and management model architecture are shown in figure 1.

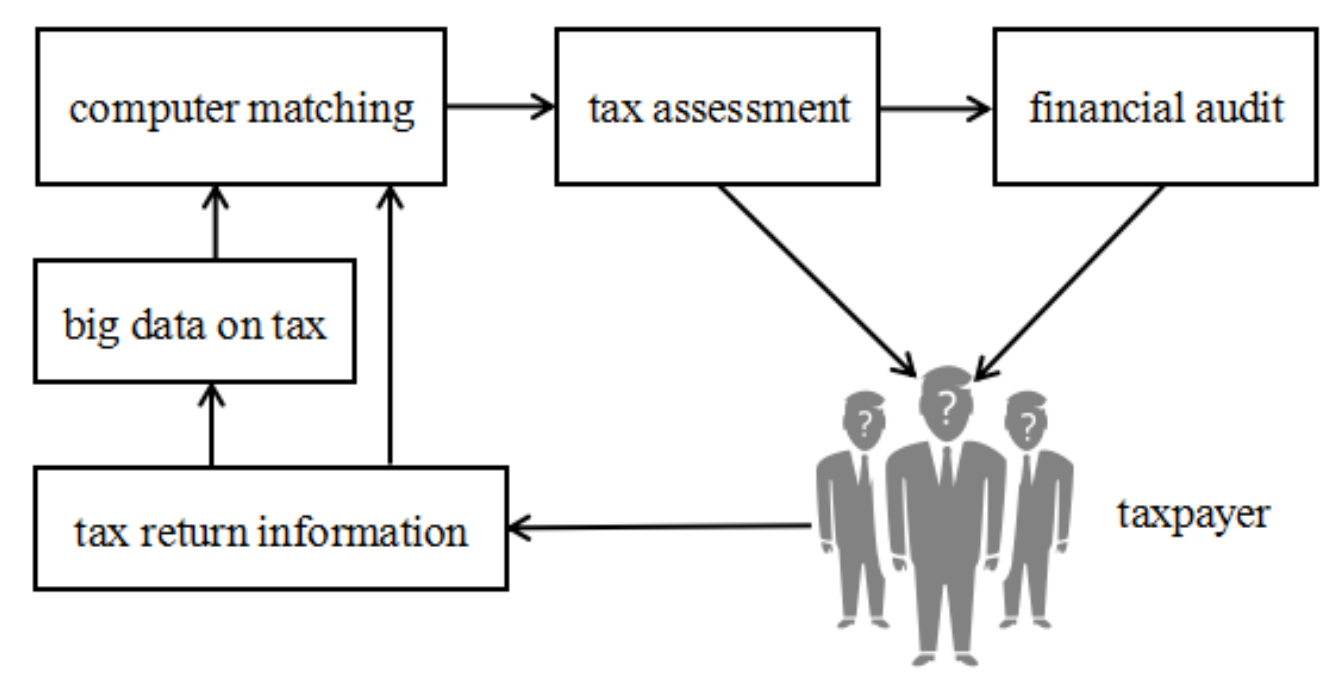

Fig.1 new tax collection and management model framework

In Figure 1, the "tax big data" refers to the integration of tax related data from both the internal and external of the tax authorities. It consists of the following parts: first, the data of tax information system refers to the data accumulated by various information systems of tax administration based on the direct collection of tax transactions and the collection of tax personnel. Second, the data provided by the taxpayer refers to the tax, invoice and financial accounting data submitted by the taxpayer when handling the tax registration, tax declaration and other services. Third, the third party data or the narrow third party, refers to the other party which has direct transaction with the taxpayer. For example, in the sale of goods, the seller is the taxpayer and the buyer is the third party. In a transaction, the third party data and the taxpayer declaration data are upstream and downstream identities, and thus can be used to verify taxpayer information. Fourth, fourth party data or the fourth party, refers to the party who has no direct transaction with the taxpayer, but for some reason also knows the transaction information. For example, property rights trading center knows the real estate transaction information for the registration of property rights of others. The Bureau of technical supervision, the Housing Management Bureau and the Union Pay are all important in the fourth party. Fifth, the fifth party data or data provided outside of the first four data, such as the media, the public and other forms of tax related data.

Construct the tax big data comparison mechanism and operation mode. First, the comparison mechanism refers to the automatic comparison between the "big tax data" and the "tax declaration data" by the computer; The mechanism tests the authenticity and accuracy of taxpayers' current declarations so as to solve the fundamental problem of information asymmetry between the publicans. Second, the new operation mode is the data processing architecture to form the three stages of computer processing, tax payment evaluation and tax inspection processing. The first step of tax data is processed by the computer on doubtful taxpayers for information asymmetry; the second step, the grass-roots tax authorities of tax assessment department makes audit analysis, interviews, investigation and verification of doubtful taxpayers, and then find and implement problems; the third step is that the tax inspection department will further investigate and punish the cases transferred by the evaluation department. 
Actively promote the formation of big tax data. In the big tax data, the tax information system data has been basically formed; as for the third party data, the tax authorities have also been in control by CTAIS; the fourth party data has a very wide range of sources and involve a complex and diverse subject; the data that has been utilized is minimal, which is a weak part of big tax data; the fifth data will take longer to perfect. In the big data of tax revenue, the fourth party data has the characteristics of integrity, authority and quantity, so it is of great value to use. However, the fourth generation data of non tax authorities is not controllable, and the tax authorities can obtain the regular channels. Therefore, expanding the fourth data is the focus of the current tax authorities in the field of promoting big data.

Promote the reform of tax authorities in a timely manner. The current tax authorities tax business process based on the set can not adapt to the new pattern of tax collection requirements. Therefore, we must set up institutions and posts in accordance with the tax information process, namely is to set up institutions and division of labor according to information collection, storage, transmission, processing, application and other function. First, it is the overall framework. According to the principle of flat trend and efficiency of the organization, the consolidated land tax bureau is a system. Second, it is the institutional function. The basic functions of the county bureau is information collection and tax assessment; the basic functions of the Provincial Bureau are the fourth party information expansion, the large data computer comparison and tax assessment and macro guidance (including industry indicators, sub sector evaluation, template parameters and early warning value evaluation and release, etc.); the State Administration of taxation may consider setting up directly under the executive board, such as the Big Data Management Bureau, the tax service bureau and so on. Among them, the basic function of the big data management bureau is big data development, data comparison, data mining and so on. Setting and reform of government institutions should change with the development of things.

\section{Summary}

Based on the problems of tax collection and management under the background of big data, this paper put forward the methods of how to make full use of advanced information technology such as big data to promote the reform of tax collection and management mode in our country. This paper argued that it should be solved from the following aspects:firstly, it is to construct new tax collection and management model; second, it is to construct taxation mechanism and operation mode of big data comparison; thirdly, it is to actively promote the formation of tax data; fourth, it is to make the timely advance tax reform.

\section{References}

[1] Dong Lei, Wang Xiangdong. The Study on the Innovation of Pipe System under the Mode of Tax Collection and Administration[J]. Tax Research, 2017, (03): 110-114.

[2] Li Rui, Li Xingying. Study on Tax Collection and Management in the Era of Big Data[J]. Journal of Southeast University (Edition of Social Science), 2015, (S2): 39-40.

[3] Lin Xiaoqian. Reform of Tax Collection and Management Model in Big Data Era[J]. Modern Economy, 2015, (35): 6-7.

[4] Wang Yao Jian, Zhou Fei, Chen Aiming. The Tax Risk Management of Large Data Based on the Background of $[\mathrm{J}]$. Tax Research, 2015, (11): 64-66.

[5] Song Jianmei. Modernization of Tax Collection and Administration: International Experience and Approaches[J]. In Modern Economy, 2015, (22): 9-11. 
[6] Liu Xinxing. Exploration and Practice of Improving the Tax Collection and Management Model of Highway Logistics Industry in China from the Perspective of Big Data[J]. Tax Economics Research, 2015, (01): 24-29.

[7] Liu Chang. Big Data Background, the Need to Reform the Tax Collection and Management Mode[J]. The Tax Levy, 2014, (12): 18-19. 